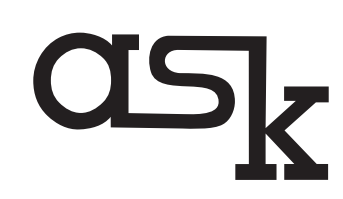

Research \& Methods ISSN 1234-9224, e-ISSN 2544-0799 Vol. 29 (1, 2020): 3-4 The Ohio State University Libraries Columbus, Ohio, USA Institute of Philosophy and Sociology Polish Academy of Sciences, Warsaw, Poland www.askresearchandmethods.org https://doi.org/10.18061/ask.v29i1.0001

\title{
Foreword for the 25th anniversary issue of ASK. Research and Methods
}

\section{Henryk Domański}

Institute of Philosophy and Sociology Polish Academy of Sciences

The development of periodical publications devoted to research methods is one answer to the constant growth in information and the need to improve instruments of social research. This special issue is dedicated to the 25th anniversary of ASK. Research and Methods. Twenty-five years ago this year, Henryk Domański, Zbigniew Sawiński, Franciszek Sztabiński, and Paweł Sztabiński from the Institute of Philosophy and Sociology of the Polish Academy of Sciences launched ASK, inspired by the growing amount of literature on this subject, and the need for a journal devoted to methods that may be applied in diverse fields. ASK was issued four times a year until 2001, since when we appear annually. Since 2008, ASK has been an international platform for methodology and comparative research that aims to present new areas, with a special focus on theoretical debates.

Concerning the list of topics published, there is a compendium of new and sometimes controversial advances in social science methodology. Contributions come from diverse areas and have something new and useful to say about a wide range of methodological questions. Issues explored include qualitative, quantitative, and mixed methods that address the full range of methodological problems confronted by empirical research. ASK provides the state-of-theart tools that researchers and academics need related to conceptualization, data analysis, data collection, measurement, modeling, and research design that may have relevance to sociological research and practice. The journal provides a forum for engaging with the ideas that underpin sociological research. Each issue of ASK presents new techniques and innovative approaches to recurring research challenges and also clarifies existing methods. ASK provides the state-of-the-art 
tools that researchers and academics like yourself need to hone your skills and increase the validity of your research findings.

Citations enable users to gather data on the "impact" of journals as well as assessing particular areas of research activity. The citation frequency of articles written in ASK has increased over time. In 1995-2008, the number of articles presented in the citation index was around five. Thereafter, a pronounced increase could be observed up until 2017, when the number of citations reached 69. During the first 15 years, the pace of citation increments was slow, even negligible. However, during the following 10 years, the frequency of these articles more than doubled (Figure 1). Most attention has been given to issues of measurement. The article New classification and occupational scales, concerning the updating of indicators of social position in Poland (2007) by Domański, Sawiński, and Słomczyński has been cited 62 times. Questions of measurement appear to have attracted the greatest attention over recent years, which was reflected in Measuring attitudes toward immigration in Europe (2012) by Meuleman and Billiet 48 citations - and in the intensity with which Evaluating measurement invariance for social and political trust in Western Europe by Davidov and Coromina was read (22), both articles based on ESS data. Relatively strong interest was also aroused by Dubrow's article on intersectionality in the quantitative analysis of survey data (27) and by Billiet, Matsuo, Beullens, and Vehovar on non-response bias in cross-national surveys (26). Concerning this upward trend, the turning point was publishing in English. Overall, since 2003 we recorded 473 citations. Learning to apply statistical techniques has prevailed as the key them; however, ASK also invites articles based on qualitative studies that deal with computerassisted qualitative data analysis software and the archivization of qualitative data.

From the very start, ASK was published by the Institute of Philosophy and Sociology of the Polish Academy of Sciences, and was joined in 2013 by Ohio State University Libraries. This publishing and archiving agreement was made possible by the organizational support of the Cross-national Studies: Interdisciplinary Research and Training Program (CONSIRT.osu.edu) of Ohio State University and the Polish Academy of Sciences. The goal was to facilitate ASK's move toward becoming an open access publication. It also enabled the digitalization and increased internalization of ASK.

We celebrate this anniversary with this special issue, composed of review articles from a number of distinguished authors. In science we perhaps too often flit from one shiny intellectual bauble to the next, without taking the time to arrange these gems into a larger treasure. But anniversaries are a time for reflection and synthesis. The authors in this issue have surveyed a broad range of topics, with a special emphasis on matters of current interest. We hope you will enjoy these contributions, as we hope you will enjoy the next twenty-five years of ASK. Research and Methods. 